\title{
Measurements of the movement of the jet streams at mid-latitudes, in the Northern and Southern Hemispheres, 1979 to 2010
}

\author{
R. D. Hudson \\ Dept. of Atmospheric and Oceanic Science, University of Maryland, College Park, MD, 20742-2425, USA
}

Correspondence to: R. D. Hudson (hudson@atmos.umd.edu)

Received: 22 August 2011 - Published in Atmos. Chem. Phys. Discuss.: 22 November 2011

Revised: 4 July 2012 - Accepted: 16 August 2012 - Published: 30 August 2012

\begin{abstract}
Previous studies have shown that the mean latitude of the sub-tropical jet streams in both hemispheres have shifted toward the poles over the last few decades. This paper presents a study of the movement of both the subtropical and Polar fronts, the location of the respective jet streams, between 1979 and 2010 at mid-latitudes, using total ozone measurements to identify the sharp horizontal boundary that occurs at the position of the fronts. Previous studies have shown that the two fronts are the boundaries of three distinct regimes in the stratosphere, corresponding to the Hadley, Ferrel, and polar meridionally overturning circulation cells in the troposphere. Over the period of study the horizontal area of the Hadley cell has increased at latitudes between 20 and 60 degrees while the area of the Polar cell has decreased. A linear regression analysis was performed to identify the major factors associated with the movement of the subtropical jet streams. These were: (1) changes in the Tropical land plus ocean temperature, (2) direct radiative forcing from greenhouse gases in the troposphere, (3) changes in the temperature of the lower tropical stratosphere, (4) the QuasiBiennial Oscillation, and (5) volcanic eruptions. The dominant mechanism was the direct radiative forcing from greenhouse gases. Between 1979 and 2010 the poleward movement of the subtropical jet streams was $3.7 \pm 0.3$ degrees in the Northern Hemisphere and $6.5 \pm 0.2$ degrees in the Southern Hemisphere. Previous studies have shown that weather systems tend to follow the jet streams. The observed poleward movement in both hemispheres over the past thirty years represents a significant change in the position of the sub-tropical jet streams, which should lead to significant latitudinal shifts in the global weather patterns and the hydrologic cycle.
\end{abstract}

\section{Introduction}

The jet streams are narrow bands of fast, meandering neartropopause winds that flow around the globe. There are two near-tropopause jet streams, the subtropical jet, imbedded in the sub-tropical upper troposphere front which is found in the poleward edge of the Hadley circulation, and the Polar jet, imbedded in the upper troposphere Polar front which is located above the Polar front zone (Holton, 1992; Bluestein, 1993). The positions of the jet streams are important because synoptic scale disturbances tend to form in the regions of maximum and minimum jet stream wind speed, and to propagate eastward along tracks that follow the jet axis (Holton, 1992). Changes in jet stream locations can therefore cause changes in the storm tracks, the global weather patterns, temperatures, precipitation and the hydrologic cycle.

Figure 1a shows an image for 11 March 1990, of the total column ozone field obtained by the National Aeronautic and Space Administration (NASA) Total Ozone Monitoring Spectrometer (TOMS) on the Nimbus-7 satellite. Hudson et al. (2003) showed that, on any day, the total column ozone field could be used to identify the position of the sub-tropical and Polar upper tropospheric fronts, the location of the subtropical and Polar jet streams, respectively. The abrupt change in the tropopause height at the frontal boundaries is manifested by an abrupt change in the total column ozone (Shalamyanskiy and Romanshkina, 1980; Keyser and Shapiro, 1986, and Karol et al., 1987). Hudson et al. (2003) developed a technique to calculate the total ozone value at the position of each frontal boundary from the total ozone daily images. They then used these ozone values to determine the geographic position of the respective fronts. Hudson et al. (2003) showed good agreement between the 


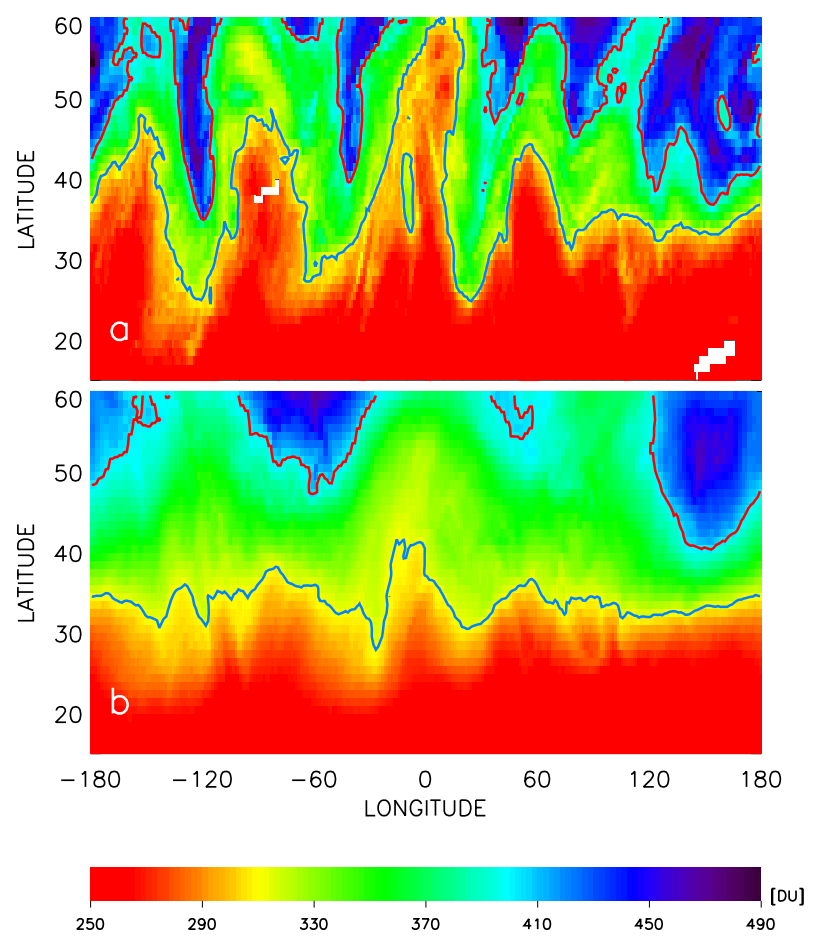

Fig. 1. (a) Total ozone image for 11 March 1990, from the TOMS instrument on the Nimbus-7 satellite. (b) Monthly average for March 1990, averaged at the pixel level. The solid blue line shows the location of the sub-tropical front, while the solid red line shows the location of the Polar front The units of the color bar are Dobson Units $\left(1 \mathrm{DU}=1\right.$ millimeter atmospheres $\left.{ }^{-1}\right)$.

position of their calculated fronts and those derived fron the NCEP/NCAR reanalysis (Kalnay, 1996; Kistler et al., 2001) using the potential vorticity on isentropic potential temperature surfaces. The position of the fronts derived from the ozone data are marked on Fig. 1a as solid lines, red (Polar front) and blue (subtropical front). The focus of the work reported here is on the net latitude movement of the two fronts as a surrogate for the movement of the two jet streams.

Hudson et al. (2006), studied the total ozone data for the Northern Hemipshere for the period from 1979 to 2004. They found that the total ozone value associated with the center of the frontal boundary on a particular day was constant with longitude, with a slight latitude dependence. They were able to identify three distinct stratospheric regimes (Tropical, mid-latitude and Polar), separated by the subtropical and Polar fronts. Within each regime the total column ozone was almost constant, again with a slight latitude dependence. In the troposphere these regimes correspond to the Hadley, Ferrell and Polar meridional cells. Hudson et al. (2003) also showed, using rawinsonde measurements, that each regime had a distinct troposphere temperature profile. In addition, FolletteCook et al. (2009), have shown that in the stratosphere each regime has a distinct ozone and water vapor profile below an altitude of about $25 \mathrm{~km}$.
Hudson et al. (2006) examined the ozone trends within each regime and concluded that, for the Northern Hemisphere, the area of the Tropical regime had increased over the period 1979 to 2003, equivalent to a northward movement of the subtropical front of about 3 degrees latitude. Previous studies have concentrated on the widening of the Tropical belt. Fu et al. (2006) examined atmospheric temperature trends in the troposphere and stratosphere over the period from 1979 to 2005, and concluded that the sub-tropical jet stream in both hemispheres had shifted poleward by $\sim 1$ degree latitude in both the summer and winter seasons. Hu and Fu (2007) examined the time evolution of the zonal meanmeridional mass streamfunctions from three reanalysis data sets, and the outgoing long-wave radiation, between 1979 and 2005. The three data sets used were the ERA-40 (Uppala et al., 2005), NCEP/NCAR (Kalnay, 1996; Kistler et al., 2001), and NCEP/DOE (Kanamitsu et al., 2002) respectively. $\mathrm{Hu}$ and $\mathrm{Fu}(2007)$ obtained a value for the expansion of the Tropical belt (defined as the latitude separation of the southern and northern sub-tropical fronts) between 2 and 4.5 degrees latitude. Seidel and Randel (2007) examined changes in the tropopause height derived from rawinsonde measurements and the NCAR/NCEP and ERA-40 reanalysis data sets. They found that between 1979 and 2005 the Tropical belt widened from between 3 and 8 degrees latitude. Davis and Rosenlof (2012) have recently intercompared the measurements of the Tropical width and conclude that the expansion is between 1.0 and 1.5 degrees per decade. The data sets used in the analyses discussed above are monthly averages obtained by averaging at each grid point in the data set. Figure $1 \mathrm{~b}$ shows the plot of the average data for March 1990 for the TOMS data set which has been obtained in a similar fashion. The dominant Rossby wave structure seen in the daily data is no longer apparent.This is because the Rossby wave structure is not static, but moves eastward with time. It should be noted that Fig. 1b is similar to other displays of the Tropical width. In this paper the area of the regimes, and the mean equivalent latitudes are derived on a daily basis and then averaged over a month. The mean monthly latitude derived in this manner for March 1990 is 38 degrees, while the value derived for Fig. $1 \mathrm{~b}$ is 34 degrees. The mean latitude seperation between the subtropical fronts in the Northern and Southern Hemispheres derived in this paper are, therefore, not the equivalent of the Tropical width. Figure 1a shows that the warm Tropical air can reach up to 60 degrees North. Of importance to climate change is the knowledge as to whether the area of the Tropical air at high latitudes has increased with time, as this would also lead to an increase in the zonal temperature at those latitudes.

As noted above, the poleward movement of the fronts implies a movement of the jet streams, which in turn implies a poleward movement of the synoptic weather patterns leading to a change in climate. It is important to understand the nature of the poleward movement of the fronts and to identify the mechanisms that are associated with this movement. This 

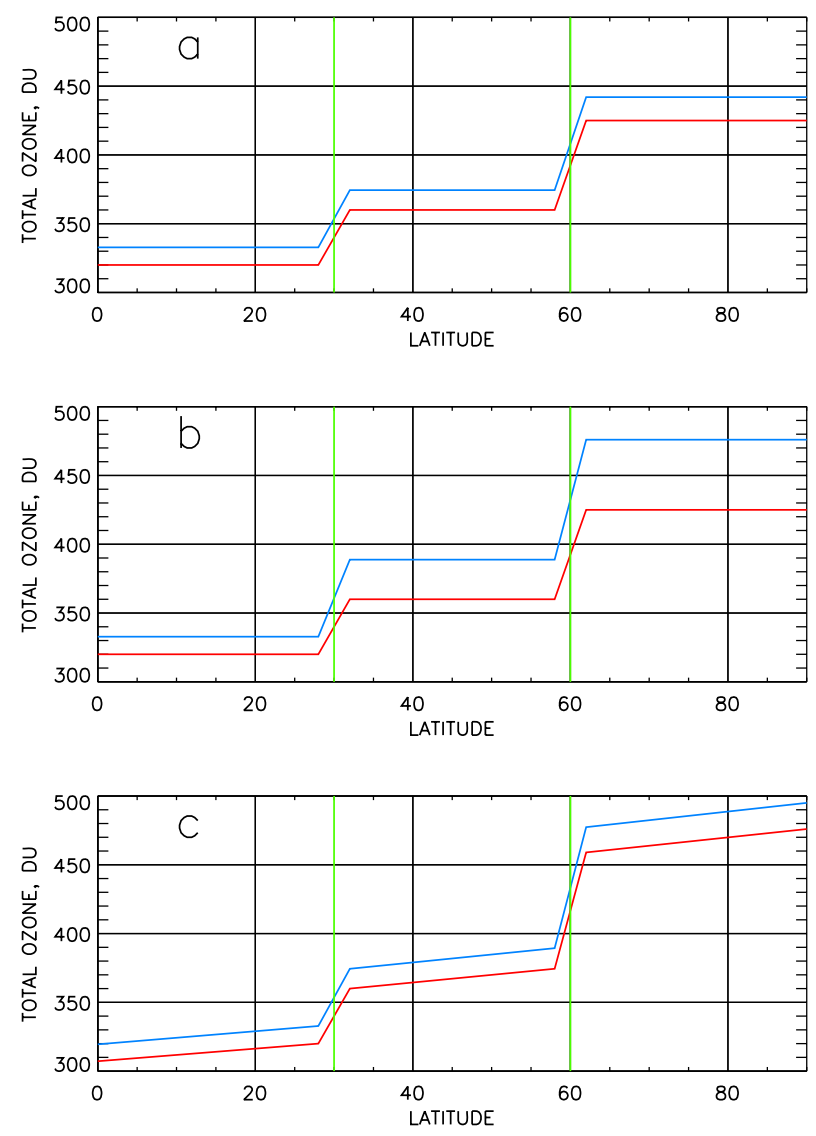

Fig. 2. Schematic of the total ozone values at the sub-tropical and Polar fronts for two instruments for three specific cases of a bias. (a) constant bias between the two data sets, (b) a bias that is a function of latitude (or total ozone amount), (c) constant bias but the total ozone value increases with latitude.

paper extends the analysis performed by Hudson et al. (2006) to both hemispheres for the time period 1979 to 2010. The study is confined to latitudes between the equator and $60^{\circ}$, the upper limit of 60 degrees being set by the spatial coverage of the total ozone data sets. A linear regression analysis is performed using selected climate indices that are believed to influence the movement of the fronts. Section 2 presents the sources of total ozone data used in the analysis. Section 3 outlines the method used to identify the frontal boundaries. Section 4 presents the analysis of the monthly mean equivalent latitudes, and Sect. 5 discusses the results of the analysis. Sec. 6 gives the conclusions of the paper.

\section{Sources of the ozone data}

In order to identify the frontal boundaries one needs daily total ozone images that cover the entire globe. The daily total ozone data used in this study were obtained from four instruments: (1) TOMS on the Nimbus-7 satellite (N7-TOMS: McPeters et al, 1996), for the period 1979-1994 (2) TOMS on the Explorer satellite (EP-TOMS: McPeters et al., 1998) for the period 1996-2006, (3) Ozone Monitoring Instrument on the AURA satellite (OMI: Bhartia et al., 2002) for the period 2004 to 2010, and (4) The Advanced Tiros-N Operational Vertical Sounder which produces the TOVS_NOAA data set (Neuendorfer, 1996) for the period 1980 to 2010. The latter data set is retrieved from several National Oceanic and Atmospheric Administration (NOAA) low Earth orbit satellites using infrared radiance measurements made by the High Resolution Infrared Sounder (HIRS) at a wavelength of 9.6 microns. The TOVS_NOAA data set is not archived by NOAA before 2002: for the time period 1980 to 2001 the TOVS data set produced by Muller et al. (2002), was used. This data set is designated as TOVS_NEURAL.

The TOMS data sets have a spatial resolution of $1.0^{\circ}$ latitude by $1.25^{\circ}$ longitude, while the OMI and TOVS data sets have a spatial resolution of $1.0^{\circ}$ latitude by $1.0^{\circ}$ longitude. All of the data sets have missing data poleward of $60^{\circ}$ latitude during the Polar night. The TOMS and OMI data sets are derived from measurements of the backscatter of solar ultraviolet radiation from the atmosphere and as such do not get results during the polar night. The TOVS data sets have a problem in the winter months when the Polar vortex is formed. The low values of total ozone that accompany the vortex cannot be resolved by the TOVS algorithms and are listed as missing data. For this reason the analysis of the frontal movement is limited to latitudes below $60^{\circ}$. There is a bias between the total ozone values obtained by the four instruments, which is a function of latitude, and/or total ozone amount. The TOVS_NEURAL data are about two per cent lower than the TOMS data, the exact amount depending on the particular instruments used, while the OMI data are about one per cent higher. As will be discussed later, the bias between the data sets does not affect the derivation of the geographic location of the fronts.

The TOVS_NOAA data set differs from the other data sets in two important ways. The day as defined in the TOVS_NOAA data goes from $0 \mathrm{Z}$ to $0 \mathrm{Z}$, while in the other data sets it goes from dateline to dateline. The geographic locations of the TOVS_NOAA data are at the latitude/longitude grid points, with dimensions of [181, 360]. For the other instruments the ozone values are the average within the box defined by the grid points and have the dimensions of [180, 288] for TOMS and [180, 360] for OMI and TOVS_NEURAL. The TOVS_NOAA data used in this analysis were first reformulated to match the other data sets. This procedure did not involve removing the bias in the original total ozone data.

\section{Determination of the ozone boundaries}

The method used to determine the latitude and longitude of the fronts for each day from the total ozone data is described in Hudson et al. (2003, 2006). The total ozone data are used 

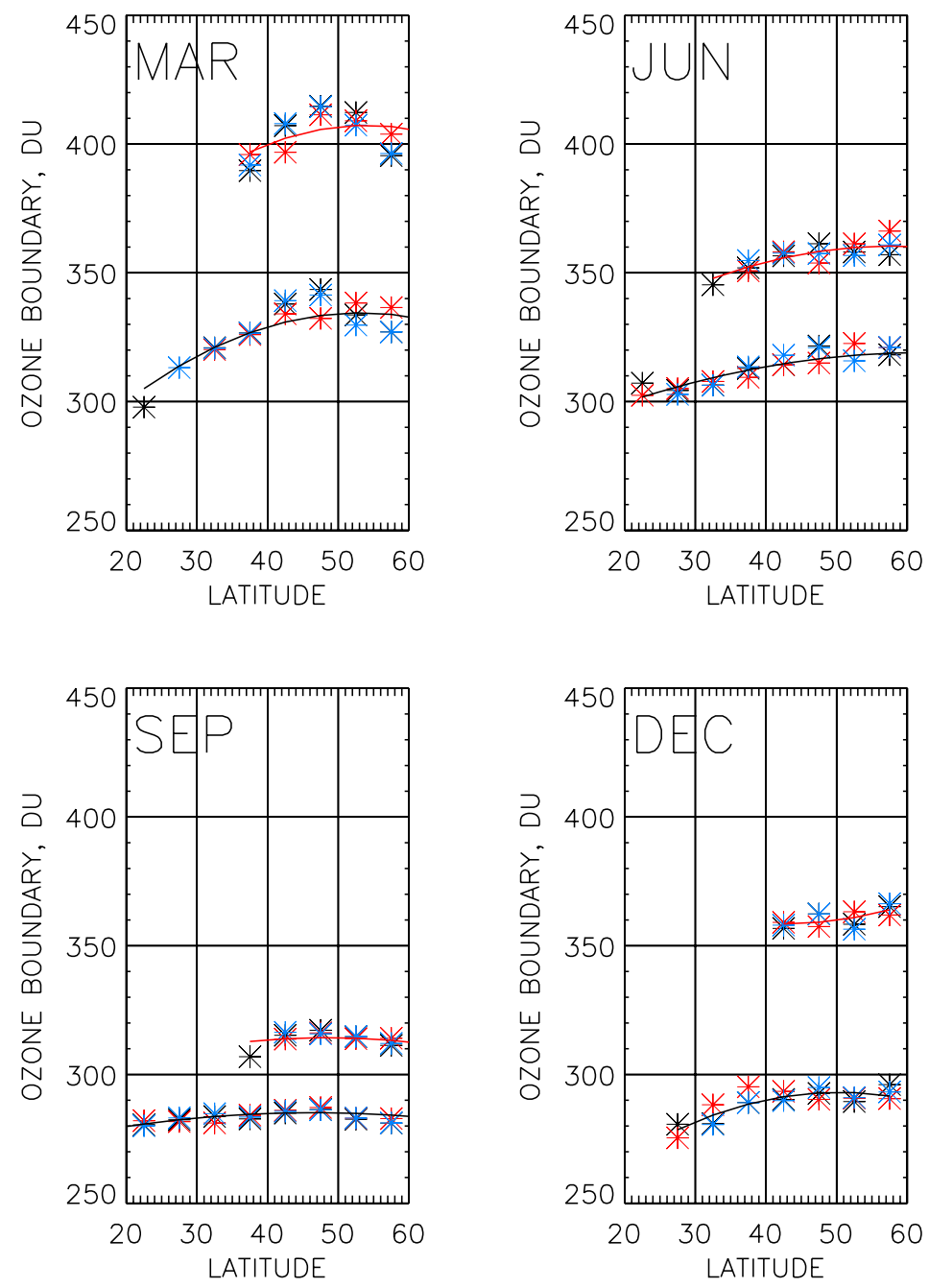

Fig. 3. Derived ozone boundaries from TOMS (red stars), TOVS (blue stars), and OMI (black stars). Data used is for the Northern Hemisphere on the 11 of each month in 2005. On each panel the upper set is for the Polar front, the lower set is for the subtropical front. The solid line is the best fit, using all three instruments, for the subtropical front (black) and the Polar front (red).

to determine the geographic coordinates of the fronts by locating the position of the increase in the total ozone amount due to the decrease in the tropopause height associated with the fronts. Figure 2 shows a schematic of the total ozone values at the fronts and compares the values for two instruments for three specific cases of a bias. Figure 2 a shows the case when there is a constant bias between the two data sets, Fig. $2 b$ shows a case where there is a bias that is a function of latitude (or total ozone amount), and Fig. 2c shows a case where the total ozone value increases with latitude. The latter case is observed typically for the winter months, indicating a drop in the tropopause height with latitude. The quantity that is retrieved from the analysis is the total ozone value at the center of the increase at the boundary. Although the value of the total ozone at the boundary differs for each instrument, the geographic coordinate of the boundary does not. A con- tour program is used to delineate the frontal boundaries and, as long as the particular derived ozone boundary value for that particular instrument is used on that instrument's data set, the geographic coordinates of the boundary should be independent of any observed bias including a long-term trend in the ozone data.

In 2005 EP-TOMS, TOVS and OMI overlap in their data coverage. Figure 3 compares the derived values of total ozone that correspond to the boundaries of the fronts for the eleventh day of March, June, September, and December of 2005. For these days only a correction has been applied to remove the bias between the data sets. The agreement between the values from each instrument is excellent, and the differences shown in Fig. 3 lead to a maximum error in the determination of the mean latitude of the frontal boundary of 0.2 degrees, which is less than the spatial resolution 

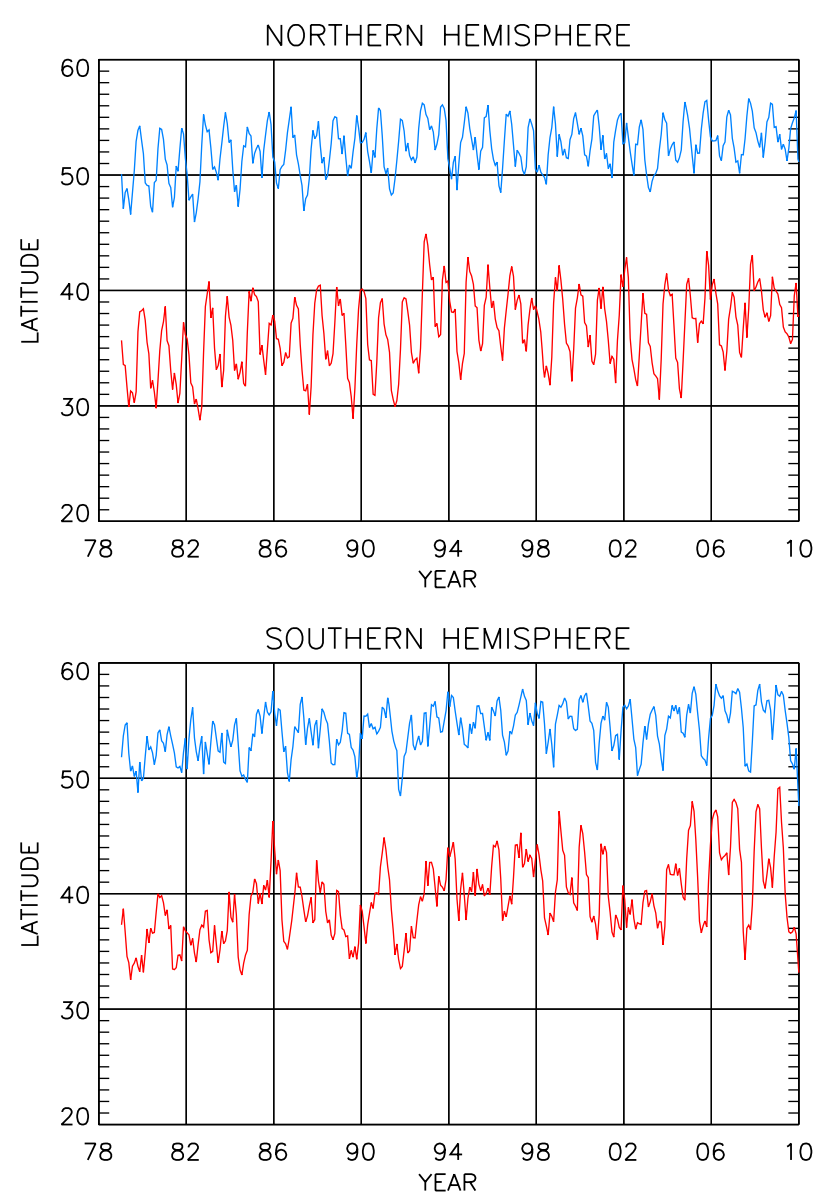

Fig. 4. Monthly mean equivalent latitude of the subtropical and Polar fronts for the Northern Hemisphere (upper panel) and the Southern Hemisphere (lower panel) for the region between the equator and $60^{\circ}$ latitude.

of the instruments. In general at least two instrument data sets can be used to derive the position of the frontal boundaries, the exception being between 1993 and 1996, when TOVS_NEURAL was the only data set available.

The spatial resolution of the total ozone data introduces an error in the determination of the latitude and longitude of the fronts. However the area of each regime can be determined with much greater accuracy. The boundaries derived from the total ozone data were used to obtain the areas of the three regimes between the equator and 60 degrees latitude (see Hudson et al, 2003, 2006 for details). The areas were calculated for each day, and then converted to an equivalent latitude. For the subtropical front, the equivalent latitude is defined as the latitude at which the zonal area from the equator to that latitude is equal to the area of the Tropical regime. For the Polar front, the area used is the sum of the Tropical and mid-latitude regimes. It should be noted that the equivalent latitude, as defined, is area weighted .
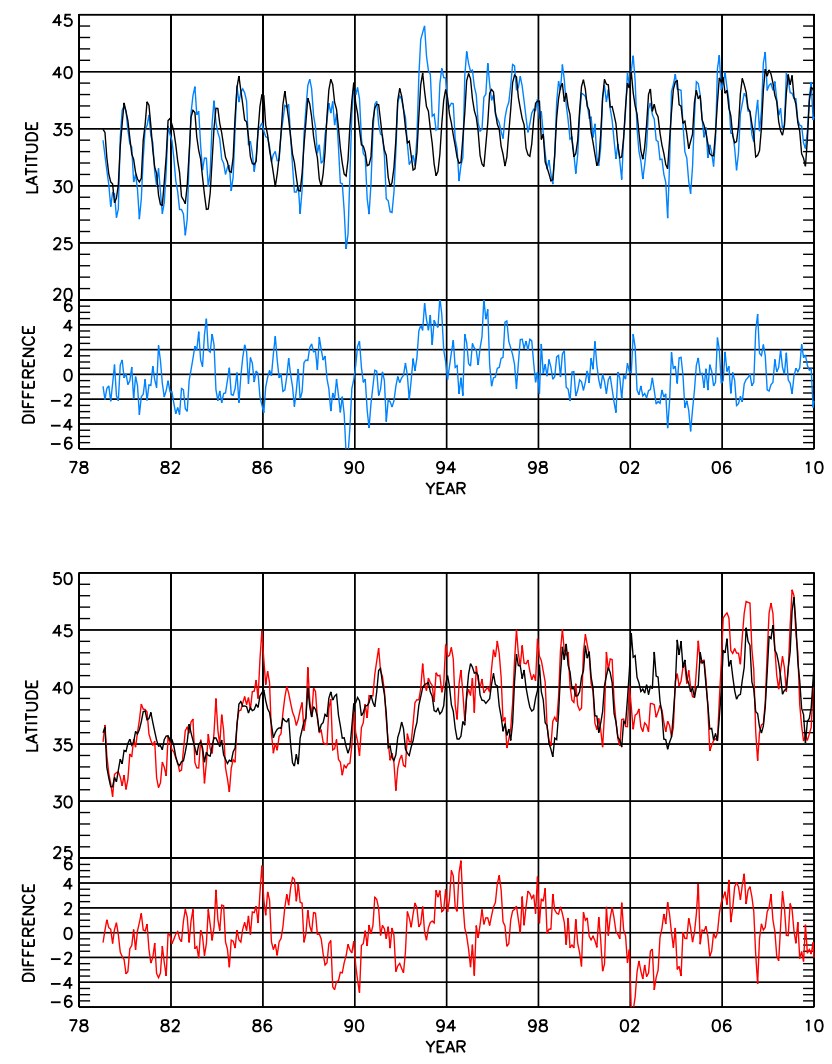

Fig. 5. Comparison of the measured monthly mean equivalent latitude of the subtropical front (red line) and the best fir from the regression analysis (black line) for the Northern and Southern Hemispheres. The blue line is a plot of the difference (measuredminus the best fit).

The monthly average used in the analysis is the mean value of the daily values for that month. The error in the monthly average used in the analysis is the standard error of the mean which includes auto-correlation. Figure 4 shows the monthly mean equivalent latitude as a function of time from 1979 to 2010 for the two fronts for the Northern and Southern Hemispheres respectively. The upper latitude of $60^{\circ}$, determined by the measurements, imposes an artificial cap on the area of the Polar regime and hence on the monthly mean equivalent latitude of the Polar front, as is shown in Fig. 4. This limits the usefulness of the data in understanding the movement of the Polar front. The $60^{\circ}$ limit also imposes a cap on the area of the Tropical regime, but the monthly mean equivalent latitude of the subtropical front is at $35^{\circ}$, and the impact is much smaller.

\section{Analysis of the monthly mean equivalent latitudes}

Lu et al., 2009, studied the possible causes of the widening of the Tropical belt. They identified four mechanisms of forcing, (1) sea surface temperature, (2) direct radiative 

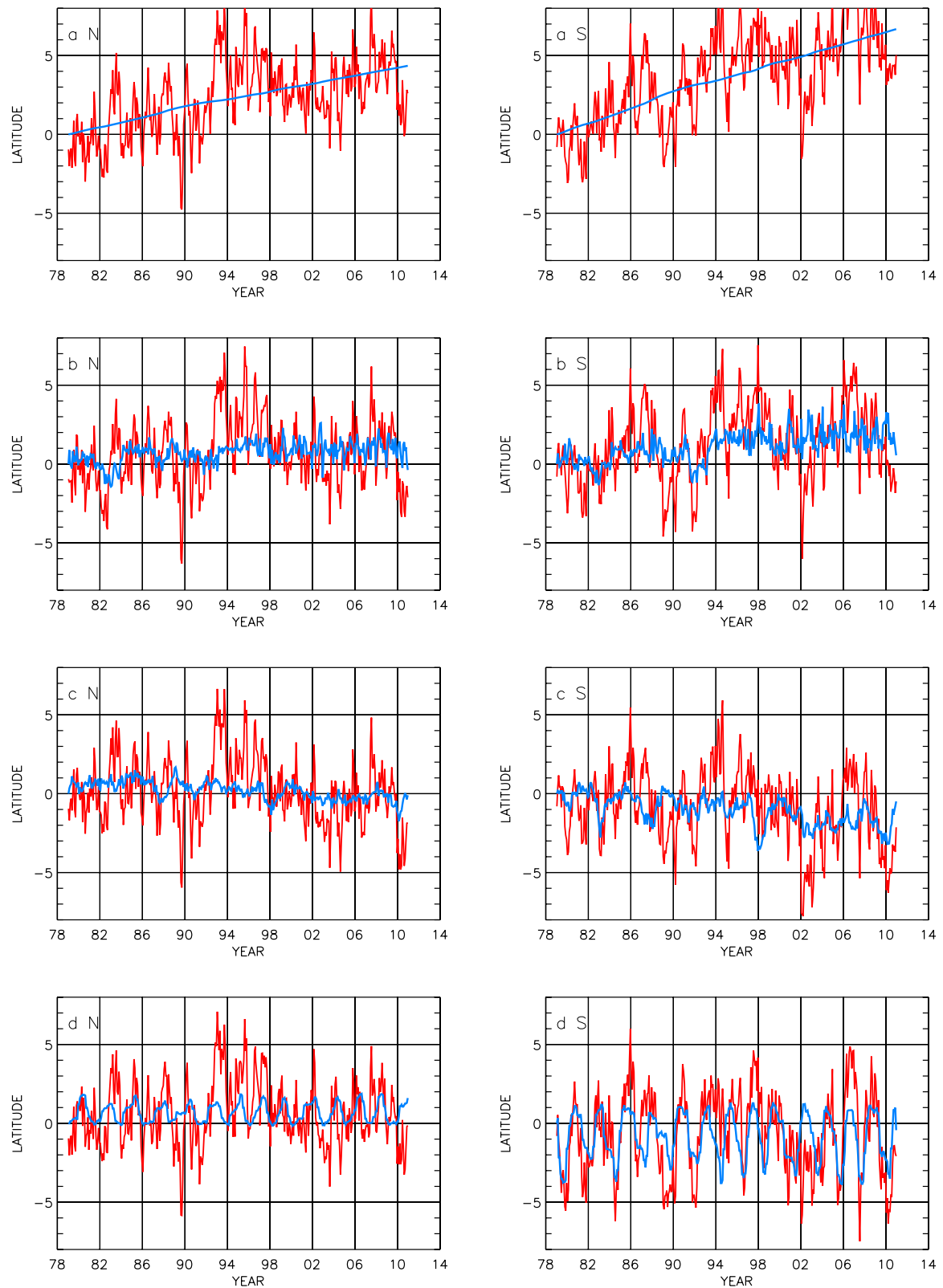

Fig. 6. Comparison between the best fit (blue line) for each climate index compared to the residual (red line) obtained from a regression analysis of the monthly mean equivalent latitude performed without that climate index: (a) (N and S) for RADF, (b) (N and S) for TEMP, (c) (N and $\mathrm{S}$ ) for ERSST, and (d) (N snd S) for QBO.

forcing from greenhouse gases in the troposphere, (3) temperature changes in the lower Tropical stratosphere due to radiative forcing, from greenhouses gases, volcanic aerosols, and changes in the stratospheric ozone concentration, and (4) variations in total solar irradiance (solar constant). In order to quantify the contributions of each of these mechanisms to the monthly mean equivalent latitude, the data were analyzed using a linear regression routine (Press et al., 1992 ). For the reasons discussed in Sect. 3, the regression analysis has been applied only to the monthly mean equivalent lati- tude of the subtropical front.The monthly errors of the mean for the equivalent latitudes, determined from the daily equivalent latitudes, were explicitly introduced into the routine and are reflected in the errors quoted for the regression constants.

Four climate indices were used in the linear regression analysis; Tropical land plus ocean surface temperature (referred hereafter as ERSST), radiative forcing in the troposphere (RADF), the lower stratosphere temperature in the tropics (TEMP) and the quasi-biennial oscillation (QBO). The ERSST used was the extended reconstruction sea surface 

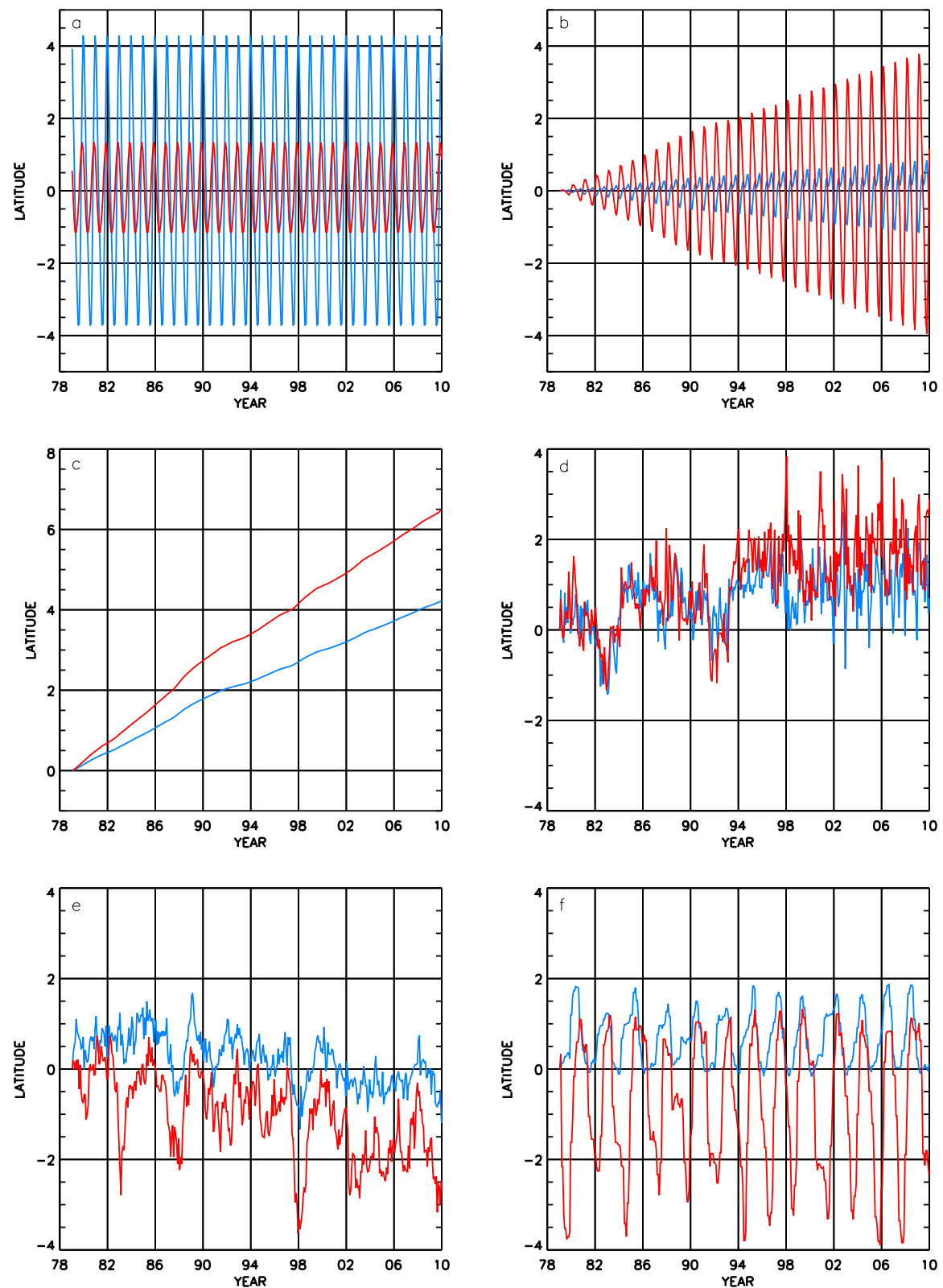

Fig. 7. Contribution of each climate index to the monthly mean equivalent latitude. The red lines are the results for the Southern Hemisphere, the blue for the Northern Hemisphere: (a) results for those seasonal terms with an amplitude independent of time, (b) results for those seasonal terms with a time dependent amplitude, (c) results for the RADF index, (d) results for the TEMP index, (e) results for the ERSST index, (f) results for the QBO index.

temperature anomaly (ERSST.v3b, Smith et al., 2008) for both land and ocean covering the latitude range 0 to $30^{\circ} \mathrm{N}$ and 0 to $30^{\circ} \mathrm{S}$. This index is based on measurements and should include the effect of any change in the solar irradiance and radiative forcing. For RADF, the NOAA annual greenhouse gas index (AGGI, Hoffman et al., 2006) was used. The TEMP index chosen was the Tropical temperature anomaly based on rawinsonde measurements (RATPAC, Free et al., 2005). This data set lists results at several pressure levels.
It was found that the data for $50 \mathrm{mb}$ gave the best fit. As TEMP is based on measurements it should include the effect of volcanic eruptions, solar irradiance and radiative forcing in the lower stratosphere, and additional indices for these effects are not needed. The QBO index was obtained from the NOAA Physical Sciences Division, Earth System Research Laboratory (www.esrl.noaa.gov/psd/data/correlation/ qbo.data), and is based on the zonal average of the $30 \mathrm{mb}$ wind at the equator. 

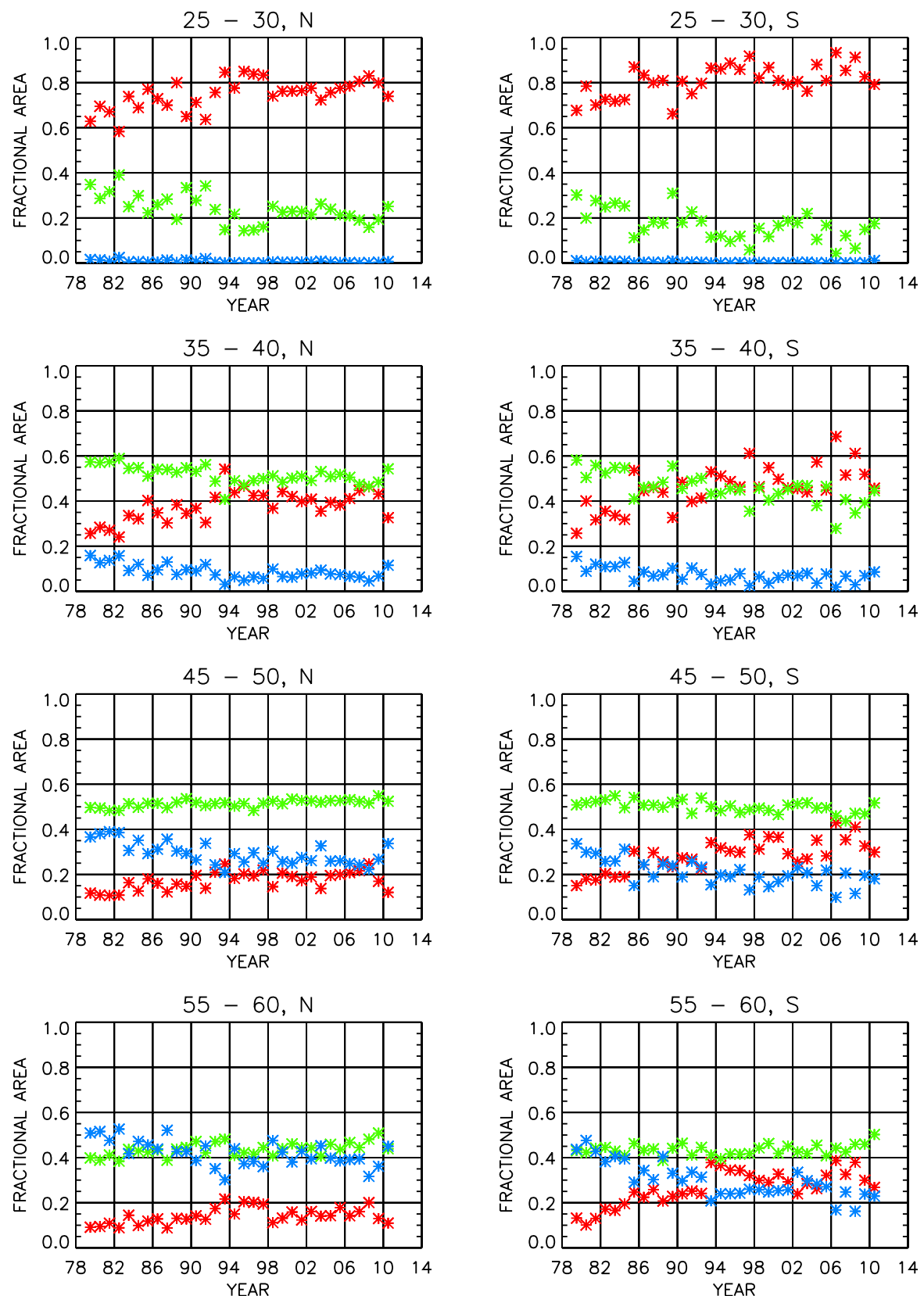

Fig. 8. The annual average fractional areas for the Tropical, mid-latitude, and Polar regimes versus time for both hemispheres, for 4 latitude bands. The Tropical regime is shown as the red stars; the midlatitude regime as the green stars, and the Polar regime as the blue stars.

Two seasonal terms (annual and semi-annual) are included, each with a sine and a cosine component. The semiannual term arises from changes in the solar irradiance at the equator which has a maximum at both the spring and autumnal equinox. The annual term reflects the movement of the inter-Tropical convergence zone (ITCZ) and solar irradiance at higher latitudes which has a maximum at the summer solstice. An examination of Fig. 4 shows that for the Southern Hemisphere, the amplitude of the seasonal terms increases with time, the dependence being almost linear with time. In the regression analysis the amplitude was assumed to have a dependence on RADF in both hemispheres. In all eight terms were included in the analysis to represent the seasonal terms. The quantities used in the regression analysis to study the movement of the subtropical front were the change in the monthly mean equivalent latitude versus the change in the indices since January 1979.

Figure 5 shows the results of the regression analysis for the Northern and Southern Hemispheres. Each panel displays the measured data, the best fit from the regression analysis, and 

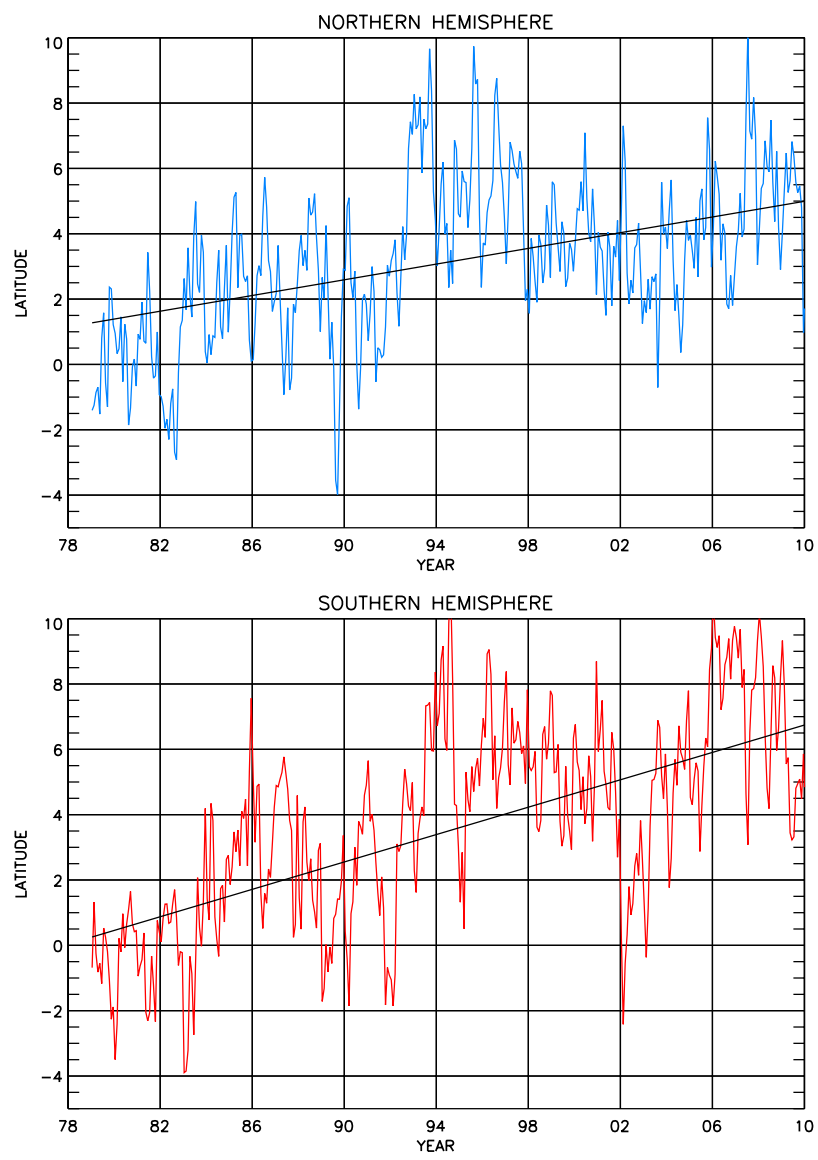

Fig. 9. Monthly mean equivalent latitude versus time for the subtropical front after the seasonal and QBO contributions have been removed. The solid black line shown for each hemisphere is the result of a linear fit, including measurement errors, to the revised data.

the difference between the measured data and the best fit. The errors in the equivalent latutitude (see Sect. 3) are propagated through the regression analysis to determine the final error of the fit and the error in the individual indices

Table 1 gives the values of the regression constants and their associated errors. The errors quoted are $2 \sigma$. Figure 6 shows a comparison of the measured data with a sequential fit to the climate indices. In the first set of panels ( $\mathrm{N}$ and $\mathrm{S}$ ) only the annual terms were included in the regression analysis. The residual (measurement-fit) is shown in red. The regression analysis was then run for the annual terms plus RADF. The blue line is the contribution from RADF to the new overall fit. In the second set of panels the red line is the residual for the annual terms plus RADF. The regression analysis was then run for the annual terms plus RADF plus TEMP; the blue line being the contribution of TEMP. This process was repeated for the other panels, adding the other indices sequentially. The purpose of Fig. 6 is to give an idea of the quality of the fit. It should be noted that each set of
Table 1. Constants of the regressions analysis for the Northern and Southern Hemisphere. The errors are $2 \sigma$.

\begin{tabular}{lrrrr}
\hline Index & Constant-N & Error-N & Constant-S & Error-S \\
\hline Temperature & -1.1 & 0.2 & -.72 & 0.07 \\
Radiative forcing & 3.6 & 0.5 & 5.2 & 0.3 \\
ERSST & -2.6 & 0.6 & -4.9 & 0.4 \\
QBO & 0.047 & 0.008 & 0.12 & 0.05 \\
$\operatorname{Sin}(\omega \mathrm{t})$ & 0.50 & 0.15 & -1.0 & 0.2 \\
$\operatorname{Cos}(\omega \mathrm{t})$ & 3.8 & 0.3 & 0.92 & 0.2 \\
$\operatorname{Sin}(2 \omega \mathrm{t})$ & -0.6 & 0.3 & -.04 & 0.2 \\
$\operatorname{Cos}(2 \omega \mathrm{t})$ & 0.48 & 0.3 & 0.10 & 0.18 \\
RADF* $\operatorname{Sin}(\omega \mathrm{t})$ & -0.43 & 0.4 & 3.3 & 0.3 \\
RADF* $\operatorname{Cos}(\omega \mathrm{t})$ & -0.48 & 0.4 & 0.69 & 0.3 \\
RADF* $\operatorname{Sin}(2 \omega \mathrm{t})$ & -0.40 & 0.4 & 0.68 & 0.3 \\
RADF* $\operatorname{Cos}(2 \omega \mathrm{t})$ & -0.33 & 0.5 & 0.30 & 0.3 \\
\hline
\end{tabular}

panels does not represent the full set of indices except for the last.

Figure 7 shows the contributions of each index to the overall fit for both hemispheres. Figure 8 shows the annual average fractional area of the three regimes from 1979 to 2010 for four latitude bands, $25^{\circ}-30^{\circ}, 35^{\circ}-40^{\circ}, 45^{\circ}-50^{\circ}$ and $55^{\circ}-$ $60^{\circ}$. Table 2 gives the slope of a linear fit including meaurement erros (Press et al., 1992) to these fractional areas for each regime expressed as a percentage. The errors in table 2 are $2 \sigma$.

In order to calculate the overall movement of the subtropical fronts over the $32 \mathrm{yr}$ time period, the effect of the seasonal and QBO terms, which are periodic, was first removed from the latitude data for each hemipshere. The results are shown in Fig. 9. The solid line in each panel of Fig. 9 is the result of a linear fit, including measurement errors (Press et al., 1992).

\section{Discussion}

\subsection{Regression analysis}

The difference plot for the Northern Hemisphere shown in Fig. 4 shows a distinct rise after 1992. The rise shows a strong corelation with the Mount Pinatubo eruption which occurred in June, 1991. A similar peak can be seen after the El Chichon eruption in April, 1982. A comparison with calculated values for the volcanic radiative forcing made by Ammann et al. (2003) shows good agreement with the shape of the difference plot, but with a lag between the radiative forcing and the movement of the front of 15 months. If the effect of the two volcanos is removed from the difference data then the difference plot is almost constant with time. An examination of the monthly mean equivalent latitude for the Northern Hemisphere appears to indicate a step change around 1990. This step change arises from the combined effect of TEMP, ERSST, QBO and the volcanic eruptions.

As noted earlier the only seasonal terms of significance were the annual and semi-annual terms. The overall 
Table 2. Increase/decrease of the area of the regimes for the Northern and Southern Hemisphere for 5 degree latitude bands between 25 and $60^{\circ}$. The change is expressed as the per cent change per decade. The errors are $2 \sigma$.

\begin{tabular}{llrrrr}
\hline $\begin{array}{l}\text { LatitudE } \\
\text { Band }\end{array}$ & Regime & $\begin{array}{r}\text { North \% } \\
\text { Change/Dec }\end{array}$ & Error & $\begin{array}{r}\text { South \% } \\
\text { Change/Dec }\end{array}$ & Error \\
\hline $25-30$ & Tropical & 2.43 & 0.28 & 2.95 & 0.22 \\
& Midlatitude & -3.11 & 0.22 & -4.16 & 0.16 \\
& Polar & & & & \\
\hline $30-35$ & Tropical & 5.17 & 0.30 & 5.96 & 0.26 \\
& Midlatitude & -4.25 & 0.26 & -6.48 & 0.24 \\
& Polar & & & & \\
\hline $35-40$ & Tropical & 5.26 & 0.24 & 5.80 & 0.24 \\
& Midlatitude & -1.8 & 0.28 & -4.58 & 0.26 \\
& Polar & -0.96 & 0.10 & -1.48 & 0.06 \\
\hline \multirow{2}{*}{$40-45$} & Tropical & 3.82 & 0.20 & 4.06 & 0.24 \\
& Midlatitude & -.451 & 0.28 & -2.82 & 0.29 \\
& Polar & -2.67 & 0.18 & -2.04 & 0.12 \\
\hline \multirow{2}{*}{$45-50$} & Tropical & 2.57 & 0.16 & 4.00 & 0.24 \\
& Midlatitude & 1.40 & 0.30 & -1.92 & 0.28 \\
& Polar & -3.29 & 0.24 & -3.51 & 0.18 \\
\hline $50-55$ & Tropical & 3.53 & 0.12 & 5.05 & 0.20 \\
& Midlatitude & 2.48 & 0.30 & 0.092 & 0.28 \\
& Polar & -4.62 & 0.14 & -4.83 & 0.24 \\
\hline $55-60$ & Tropical & 4.08 & 0.11 & 5.96 & 0.22 \\
& Midlatitude & 2.05 & 0.32 & 0.02 & 0.30 \\
& Polar & -3.79 & 0.30 & -8.29 & 0.24 \\
\hline \multirow{2}{*}{5} & & & &
\end{tabular}

contribution of the seasonal term with a constant amplitude is shown in Fig. $7 \mathrm{a}$ and that for the amplitude proportional to RADF is shown in Fig. 7b. Over the course of a year the range of the amplitude of the constant seasonal term is $7.8^{\circ}$ in latitude for the northern subtropical front and 2.6 degrees for the southern subtropical front. In the Southern Hemisphere the range of the RADF dependent amplitude has increased by $7.1^{\circ}$ from 1979 to 2010, while that for the Northern Hemispohere has increased by 1.4 degrees. For the Northern Hemisphere the maximum of the constant annual term occurs in January while for the Southern Hemisphere it occurs in November. The semi-annual term peaks in June and December in both the Northern and Southern Hemispheres. The maximum of the RADF dependent annual term occurs in August for the Northern Hemisphere, and March for the Southern Hermisphere. The RADF semi-annual term peaks in October and April in the Northern Hemisphere, August and February in the Southern Hemisphere. The sum of the seasonal terms peaks in November/December in the Northern Hemispehere and in March in the Southern Hemisphere.

Figures $6 \mathrm{a}$ and $7 \mathrm{c}$ show the dependence of the latitude of the subtropical front on the tropospheric radiative forcing. The effect is large and is positive. Over the period of the study the subtropical front has moved by $4.2^{\circ}$ in the Northern Hemisphere and $6.9^{\circ}$ in the Southern Hemisphere.
Figures $6 \mathrm{~b}$ and $7 \mathrm{~d}$ show the effect of temperature change in the lower stratosphere on the movement of the fronts. Over the past 30 years the effect has introduced a latitude shift of about $1^{\circ}$ in the Northern Hemisphere and 1.5 degrees in the Southern Hemisphere. This implies that a cooling of the lower stratosphere moves the front towards the pole, in agreement with the theoretical analysis of Lu et al. (2009).

Figures $6 \mathrm{c}$ and $7 \mathrm{e}$ show the dependence of the frontal movement on the Tropical land and ocean mean temperature anomaly ( 0 to $30^{\circ}$ latitude). An increase in the value of the ERSST leads to a decrease in the latitude of the subtropical front by about 2 degrees in the Southern Hemisphere and 0.5 degrees in the Northern Hemisphere. The latitude shift has the same sign as the results obtained by Lu et al., 2009. Figure $5 \mathrm{~d}$ and $6 \mathrm{f}$ show the dependence on the QBO. There is a much stronger dependence in the Southern Hemisphere than in the Northern Hemisphere. An increase in the QBO leads to an increase in the latitude of the subtropical front. Over a typical QBO cycle the front moves about $1.5^{\circ}$ in the Northern Hemisphere, and $3.5^{\circ}$ in the Southern Hemisphere.

\subsection{Latitude bands}

Figure 8 and Table 2 show that the fractional area of the tropical regime has increased from 1979 to 2010 at all latitude 
bands in both hemipsheres. The area of the mid-latitude regime in the Northern Hemipshere decreases at latitudes less than 45 degrees, and increases at latitudes greater than 45 degrees. In theSouthern Hemipshere, the area of the midlatitude regime decrerases at all latitudes. The area of the polar regime decreases at all latitudes in both hemispheres.

As noted before, Hudson et el., 2003, showed that each regime had a distinct troposphere temperature profile over a large latitude range. The global temperature changes discussed in the Intergovermental Panel on Climate Change 2007 assessment report, AR4 (IPCC, 2007) are based on zonal averages. Let the mean ground temperature within the latitude zone, for the Tropical regime be defined as $T_{\mathrm{t}}$, for the mid-latitude regime as $T_{\mathrm{m}}$, and for the Polar regime as $T_{\mathrm{p}}$. Then the mean zonal temperature, $T$, is given by:

$T=T_{\mathrm{t}} \times A_{\mathrm{t}}+T_{\mathrm{m}} \times A_{\mathrm{m}}+T_{\mathrm{p}} \times A_{\mathrm{p}}$

Where $A_{\mathrm{t}}, A_{\mathrm{m}}$ and $A_{\mathrm{p}}$ are the fractional areas of the regimes within the latitude zone such that:

$A_{\mathrm{t}}+A_{\mathrm{m}}+A_{\mathrm{p}}=1.0$.

In general $T_{\mathrm{t}}>T_{\mathrm{m}}>T_{\mathrm{p}}$ and thus an increase in $A_{\mathrm{t}}$ and a decrease in $A_{\mathrm{m}}$ and $A_{\mathrm{p}}$ will lead to an increase in $T$. This trend will contribute to the overall observed temperature trend.

\section{Conclusions}

Between 1979 and 2010 the subtropical front has moved poleward by $3.7 \pm 0.3$ degrees in the Northern Hemisphere and $6.5 \pm 0.2$ degrees in the Southern Hempisphere. As mentioned in Sect. 1, Seidel and Randel (2007) performed a study of the expansion of the tropical belt using tropopause height measurement from rawinsondes. They obtained an expansion of from 5 to 8 degrees from the rawinsonde data. This result has been critisized by Birner, 2010. For innapropriate use of absolute thresholds to define the tropical boundaries. The tropopause heights used in the analysis of Seidel and Randel (2007) are equivalent to the picture shown in Fig. 1a not b. At each rawinsonde station they would encounter, with time, distinctly different tropopause heights, of the order of $16 \mathrm{~km}$ within the Hadley cell, $12 \mathrm{~km}$ within in the Ferrel cell and $8 \mathrm{~km}$ within the Polar cell, as the Rossby waves move around the globe. These changes are well outside any experimental error in the rawinsonde data. For the period from 1979 to 2005 the latitude difference between the Northern and Southern sub-tropical fronts obtained from the total ozone data has increased by 8.3 degrees, at the upper limit of the range of 3-8 degrees obtained by Seidel and Randel (2007).

A regression analysis was preformed consisting of terms for Tropical land plus ocean surface temperaature, radiative forcing in the troposphere, the lower stratosphere temperature in the tropics and the quasi-biennial oscillation. Of these four indices, the radiative forcing made the largest contribution to the poleward movement. Weather systems tend to follow the jet streams which are imbedded in the fronts. Hence a poleward movement of the fronts leads to a net movement of the weather patterns towards the poles. IPCC (2007), reports a shift in the storm track locations, increased storm activity accompanied by a decrease in storm numbers over the past thirty years. The observed poleward movement in both hemispheres over the past thirty years represents a significant change in the position of the jet streams, which should lead to significant latitudional shifts in the global weather patterns, temperatures, precipitation and the hydrologic cycle.

Acknowledgements. The author wishes to thank the editor and the reviewers for their insightful comments and criticisms. The author wishes to acknowledge helpful comments from M. Andrade, and T. Canty, who kindly agreed to read an earlier version of the manuscript.

Edited by: T. J. Dunkerton

\section{References}

Archer, C. and Caldiera, K.: Historical trends in the Jet Streams, Geophys. Res. Lett., 35, L08803, doi:1029/2008GL033614, 2008.

Amman, C. M., Meehl, G. A., Washington, W. M., and Zander, C. S.: A monthly and latitudionally varying volcanic forcing data set in simulations of the 20th century climate, Geophys. Res. Lett., 30, 1657, doi:1029/2003GL016875, 2003.

Birner, T.: Recent widening of the tropical belt from global tropopause statistics: Sensitivities, J. Geophys. Res., 115, D23109, doi:10.1029/2010JD014664, 2010.

Bluestein, H. B.: Synoptic-Dynamic Meteorology in Midlatitudes, Vol. 2, Observations and Theory of Weather Systems, 594 pp., Oxford Univ. Press, New York, USA, 1993.

Davis, S. and Rosenlof, K.: A Multidiagnostic Intercomparison of Tropical-Width Time Series Using Reanalysis and Satellite Observations, J. Climate, 25, 1061-1078, doi:10.1175/JCLI-D-1100127.1, 2012.

Follette-Cook, M. B., Hudson, R. D., and Nedoluha, G. E.: Classification of Northern Hemisphere stratospheric ozone and water vapor profiles by meteorological regime, Atmos. Chem. Phys., 9, 5989-6003, doi:10.5194/acp-9-5989-2009, 2009.

Free, M., Seidel, D. J., Angell, J. K., Lanzante, J., Durre, I., and Peterson, T. C., Radiosonde Atmospheric Temperature Products for Assessing Climate (RATPAC): A new data set of large-area time series, J. Geophys. Res., 110, D22101, doi:10.1029/2005JD006169, 2005.

Fu, Q., Johanson, C. M., Wallace, J. M., and Reichler, T., Enhanced Mid-Latitude Tropospheric Warming in Satellite Measurements, Science, 312, 1179, doi 10.1126/science.1125566, 2006.

Hoffman D. J., Butler, J. H., Dlugokencky, E. J., Elkins, J. W., Masarie, K., Montzka, S. A., and Tans, P., The role of carbon dioxide in climate forcing from 1979 to 2004: Introduction of the Annual Greenhouse Gas Index, Tellus B, 58B, 614-619, 2006. 
Holton, J. R.: An Introduction to Dynamic Meteorology, 511 pp., Elsevier, New York, USA, 1992.

$\mathrm{Hu}$, Y. and $\mathrm{Fu}, \mathrm{Q}$., Observed poleward expansion of the Hadley circulation since 1979, Atmos. Chem. Phys., 7, 5229-5236, doi:10.5194/acp-7-5229-2007, 2007.

Hudson, R. D., Andrade, M., Follette, M. B., and Frolov, A. D.: The total ozone field separated into meteorological regimes-Part I: Defining the regimes, J. Atmos. Sci., 62,1669-1677, 2003.

Hudson, R. D., Andrade, M. F., Follette, M. B., and Frolov, A. D.: The total ozone field separated into meteorological regimes Part II: Northern Hemisphere mid-latitude total ozone trends, Atmos. Chem. Phys., 6, 5183-5191, doi:10.5194/acp-6-5183-2006, 2006.

IPCC, Climate Change 2007: The Physical Science Basis. Contribution of Working Group 1 to the Fourth Assessment Report of the Intergovermental Panel on Climate Change, edited by: Solomon, S., Qui, D., Manning, M, Chen, Z., Marquis, M., Avery, K. B., Tigner, M., and Miller, H. L, Cambridge University press, Cambridge U. K. and New York, NY, USA, 996 pp., 2007.

Kanamitsu, M., Ebisuzak, W., and Woollen, J., NCEP-DOE AMPII reanalysis (R-2), Bull. Am. Meteorol. Soc., 83, 1631-1641, 2002.

Kaffel, A. K. and Müller, M. J.: Results of neural network total ozone retrieval on global NOAA_TOVS data, Technical Proceedings of the $10^{\text {th }}$ International ATOV Study Conference, edited by: La Marshall, J., and Jasper, J. D., Bureau of Meteorology Research Centre, Melbourne, Australia, 268-275, 1999.

Kalnay, E., Kanamitsu, M., Kistler, R., Collins, W., Deaven, D., Gandin, L., Iredell, M., Saha, S., White, G., Woollen, J., Zhu, Y., Chelliah, M., Ebisuzaki, W., Higgins, W., Janowiak, J., Mo, K. C., Ropelewski, C., Wang, J., Leetmaa, A., Reynolds, R., Jenne, R., and Joseph, D., The NMC/NCAR 40-Year Reanalysis Project, B. Am. Meteorol. Soc., 77, 437-471, 1996.

Karol, I. L., Klyagina, L. P., Frolov, A. D., and Shalamyansky, A. M.: Fields of ozone and temperature within the boundaries of air masses, Meteorol. Gidrol., 10, 47-52, 1987.

Keyser, D., Shapiro, M. A., A Revire of the Structure and Dynamics of Upper-level Frontal Zones, Mon. Weather Rev., 114, 452-499, 1986.

Kistler, R., Kalnay, E., Collins, W., Saha, S., White, G., Woollen, J., Chelliah, M., Ebisuzaki, W., Kanamitsu, M., Kousky, V., van den Dool, H., Jenne, R., and Fiorino, M., The NCEP-NCAR 50Year Reanalysis: Monthly Means CD-ROM and Documentation, B. Am. Meteorol. Soc., 82, 247-268, 2001.
Lu, J., Deser, C., and Reichler, T.: Cause of the widening of the tropical belt since 1958, Geophys. Res. Lett., 36, L03803, doi:10.1029/2008GL036076, 2009.

McPeters, R., Bhartia, P.K., Kruger, A., Herman, J., Schlesinger, B., Wellermeyer, C., Seftor, C., Jaross, G., Taylor, S., Swissler, T., Torres, O., Byerly, W., and Cebula, R., Nimbus-7 Total Ozone Mapping Spectrometer (TOMS) Data Products User's Guide, NASA Reference Publication 1384, National Aeronautic and Space Administration, Washington, DC, USA, 1996.

McPeters, R., Bhartia, P. K., Kruger, A., Herman, J., Wellermeyer, C., Serafino, C., Jaross, G., Torres, O., Moy, L., Labow, G., Byerly, W., Taylor, S., Swissler, T., and Cebula, R., Earth Probe Total Ozone Mapping Spectrometer (TOMS) Data Products User's Giude, NASA Technical Report TR_1998-206895, National Aeronautic and Space Administration, Washington, DC, USA, 1998.

Neurenforfer, A, M.: Ozone monitoring with TIROS-N operational vertical sounders, J. Geophys. Res., 101, 18807-18828, 1996.

Press, W. H., Teuskojsky, S. A., Vettering, W. T., and Flannering, B. P.: Numerical recipes in C, 960 pp., Cambridge University Press, New York, NY, USA, 1992.

Seidel, D. and Randel, W. J.: Recent widening of the tropical belt: Evidence from tropical observations, J. Geophys. Res., 112, D20113, doi:10.1029/2007JD008861, 2007.

Shalamyanskiy, A. M. and Romashkina, A. K.: Distribution and variation in the total ozone concentration in various air masses, Izv. Atmos. Oceanic Phys., 16, 931-937, 1980.

Smith, T. M., Reynolds, R. W., Petersen, T. C., and Lavrinmore, J.: Improvements to NOAA's Historical Merged Land-Ocean Surface Temperature Analysis (1880 to 2006), J. Climate, 21, 2283 2296, 2008.

Uppala, S.M., Kållberg, P.W., Simmons, A.J., Andrae, U., da Costa Bechtold, V., Fiorino, M., Gibson, J.K., Haseler, J., Hernandez, A., Kelly, G.A., Li, X., Onogi, K., Saarinen, S., Sokka, N., Allan, R.P., Andersson, E., Arpe, K., Balmaseda, M.A., Beljaars, A.C.M., van de Berg, L., Bidlot, J., Bormann, N., Caires, S., Chevallier, F., Dethof, A., Dragosavac, M., Fisher, M., Fuentes, M., Hagemann, S., Hólm, E., Hoskins, B.J., Isaksen, L., Janssen, P.A.E.M., Jenne, R., McNally, A.P., Mahfouf, J.-F., Morcrette, J.J., Rayner, N.A., Saunders, R.W., Simon, P., Sterl, A., Trenberth, K.E., Untch, A., Vasiljevic, D., Viterbo, P., and Woollen, J., The ERA-40 re-analysis, Q. J. Roy. Meteorol. Soc., 131, 2961-3012, 2005. 